\title{
Lansky Performance Status 70
}

National Cancer Institute

\section{Source}

National Cancer Institute. Lansky Performance Status 70. NCI Thesaurus. Code C69423.

Both greater restriction of and less time spent in play activity. 